\title{
REVIEW
}

Open Access

\section{Influence of exposing dental implants into the sinus cavity on survival and complications rate: a systematic review}

\author{
Gian Maria Ragucci ${ }^{1}$, Basel Elnayef ${ }^{f^{*}}$, Fernando Suárez-López del Amo², Hom-Lay Wang ${ }^{3}$, \\ Federico Hernández-Alfaro ${ }^{1}$ and Jordi Gargallo-Albiol ${ }^{1}$
}

\begin{abstract}
Background: After tooth loss, the posterior maxilla is usually characterized by limited bone height secondary to pneumatization of the maxillary sinus and/or collapse of the alveolar ridge that preclude in many instances the installation of dental implants. In order to compensate for the lack of bone height, several treatment options have been proposed. These treatment alternatives aimed at the installation of dental implants with or without the utilization of bone grafting materials avoiding the perforation of the Schneiderian membrane. Nevertheless, membrane perforations represent the most common complication among these procedures. Consequently, the present review aimed at the elucidation of the relevance of this phenomenon on implant survival and complications.
\end{abstract}

Material and methods: Electronic and manual literature searches were performed by two independent reviewers in several databases, including MEDLINE, EMBASE, and Cochrane Oral Health Group Trials Register, for articles up to January 2018 reporting outcome of implant placement perforating the sinus floor without regenerative procedure (lateral sinus lift or transalveolar technique) and graft material. The intrusion of the implants can occur during drilling or implant placement, with and without punch out Schneiderian. Only studies with at least 6 months of follow-up were included in the qualitative assessment.

Results: Eight studies provided information on the survival rate, with a global sample of 493 implants, being the weighted mean survival rate $95.6 \%$ (IC 95\%), after 52.7 months of follow-up. The level of implant penetration ( $\leq 4$ $\mathrm{mm}$ or $>4 \mathrm{~mm}$ ) did not report statistically significant differences in survival rate $(p=0.403)$. Seven studies provided information on the rate of clinical complications, being the mean complication rate 3.4\% (IC 95\%). The most frequent clinical complication was epistaxis, without finding significant differences according to the level of penetration. Five studies provide information on the radiographic complication; the most common complication was thickening of the Schneiderian membrane. The weighted complication rate was 14.8\% (IC 95\%), and penetration level affects the rate of radiological complications, being these of $5.29 \%$ in implant penetrating $\leq 4 \mathrm{~mm}$ and $29.3 \%$ in implant penetrating $>4 \mathrm{~mm}$, without reaching statistical significant difference $(p=0.301)$.

(Continued on next page)

\footnotetext{
* Correspondence: baselnsk@gmail.com

${ }^{1}$ Department of Oral and Maxillofacial Surgery, International University of Catalonia, C/Josep Trueta Sn, Sant Cugat del Vallés, C.P 08195 Barcelona, Spain

Full list of author information is available at the end of the article
} 


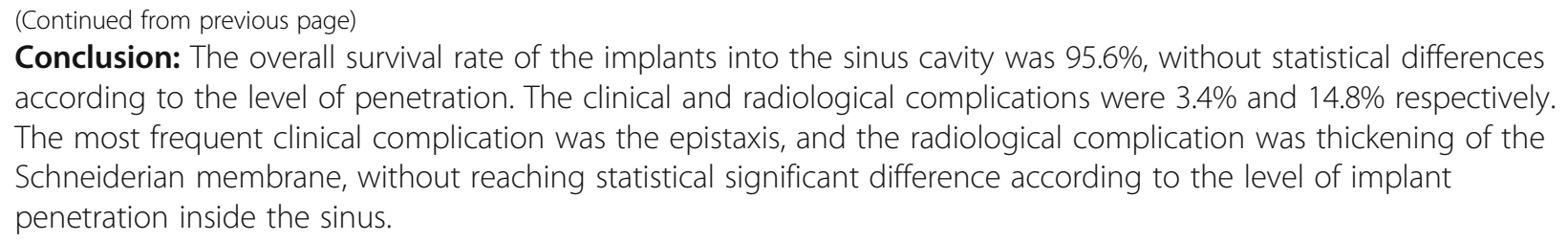

Keywords: Maxillary sinus, Dental implant, Maxillary sinusitis, Sinusitis, Bone regeneration, Bone grafting,

\section{Introduction}

The edentulous posterior maxillary region often presents with unique challenging conditions in implant dentistry [1]. Limited bone height secondary to pneumatization of the maxillary sinus and the resorption of the alveolar ridge preclude in many instances the installation of dental implants. To compensate for the lack of bone height, several treatment options have been proposed.

The most conservative and minimally invasive technique is the placement of short implants with less technically demanding operation, lower expense, fewer surgical procedures, and fewer complications [2-6]. Another therapeutic alternative is to use the residual, taking advantage of the residual bone, present in the anatomic buttress, as the frontomaxillary, frontozygomatic, and pterygomaxillary buttress [7], using zygomatic implants or pterygoid implants, combined with anterior standard implants; both of them have reported good survival and success rate [8-10]. Another alternative is regenerative procedure of the maxillary sinus encompassed by two main approaches: the lateral windows approach and the transalveolar or crestal approach. The technique of sinus augmentation was first published in 1980 by Boyne and James [11] and subsequently by Tatum [12]. It is most often used when severe degree of resorption is present, which precludes the installation of short implants and/ or the achievement of primary stability. The transalveolar or crestal approach was first described by Summers [13] in 1996. This approach is commonly used when the degree of resorption is lower, and it is possible in the installation of dental implants with primary stability. Both techniques have shown high survival rates [14] similar to those implants installed in the non-grafted posterior maxilla [15].

The maxillary sinus is a paired pyramid-shaped paranasal cavity lined with thin respiratory ciliated epithelium that serves in the transportation of fluid secretions toward the ostium. This lining of the maxillary sinus cavity is called the Schneiderian membrane [16]. The integrity of the membrane is of paramount importance for the performance of sinus augmentation procedures and the avoidance of potential complications [17, 18]. However, perforation of the membrane remains as the most commonly occurring complications approximately in
$15.7 \%$ of the cases [19]. Moreover, this complication can occur inadvertently. However, some evidence suggested that these perforations seem not to have a detrimental effect on implant survival or the appearance of further complications. In fact, recent investigations have found greater vital bone when perforations occurred [20]. As such, the survival rate does not differ between implants placed in perforated and non-perforated sinuses not statistically significantly different [21-23].

Intrusion of dental implants into the maxillary sinus perforating through the Schneiderian membrane is considered a cause of undesirable complications [24, 25]. However, this phenomenon has never been properly evaluated and systematically studied. For this reason, the aim of this systematic review was to assess the implant survival and complication rates of implants intruding into the sinus cavity.

\section{Materials and methods}

This systematic review and subsequent meta-analysis follow the guidelines of the PRISMA statement.

\section{Focus question}

The following focus question was developed: Is the intrusion of dental implants into the sinus cavity during implant drilling or implant placement, without regenerative procedure (lateral sinus lift or transalveolar technique) and graft material, has an effect on implant survival or increase clinical and radiographic complications? (Fig. 1) (Table 1).

Implant survival was defined as no pain on function, no mobility, 2-4 $\mathrm{mm}$ radiographic bone loss, and no exudates history.

Implant success was defined as no pain or tenderness upon function, no mobility, $+2 \mathrm{~mm}$ radiographic bone loss from initial surgery, and no exudates history.

\section{Selection study}

An electronic literature search was conducted by two independent reviewers (GMR and BE) based on the inclusion criteria in several databases, including MEDLINE, EMBASE, the Cochrane Central Register of Controlled Trials, and the Cochrane Oral Health Group Trials Register databases, covering articles written in English 

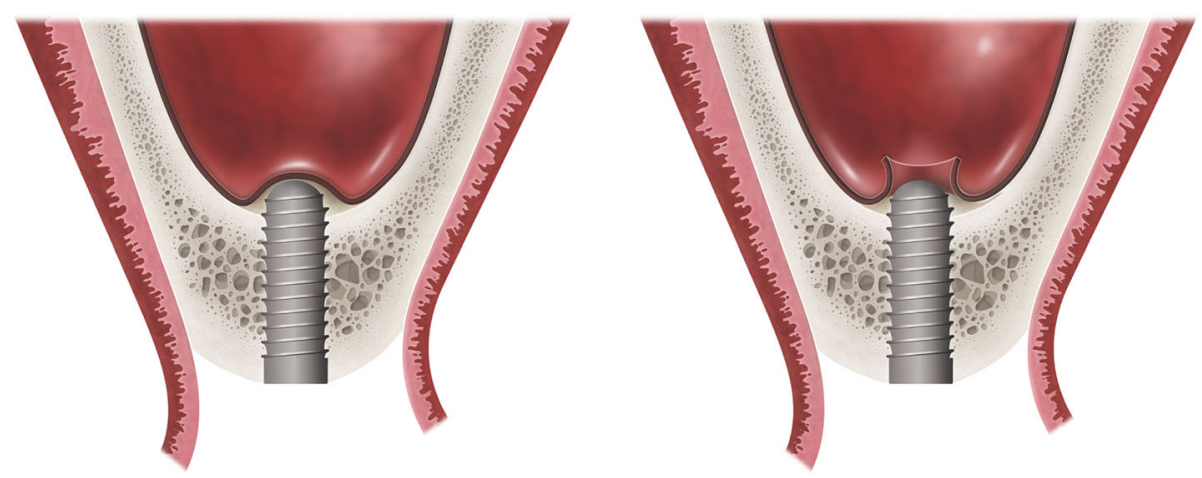

Fig. 1 Graphic representation of implants intruding sinus perforating or not the Schneiderian membrane

up until January 2018. Because no randomized controlled trials were found in the screening process, the included studies were analyzed with Newcastle-Ottawa scale (NOS). Both reviewers compared decisions, and their eligibility for this review was confirmed after discussion. Full articles were obtained for all the investigations deemed eligible for inclusion in this paper and further evaluated by both reviewers. If needed, a third reviewer was consulted to ensure consensus.

\section{Screening process}

Literature search was conducted in several databases including MEDLINE (PubMed) and EMBASE from 1980 to 2018. All article titles and abstracts were screened in order to eliminate non-qualifying studies. Next, full-text evaluation of each article was performed in order to confirm the eligibility based on the inclusion and exclusion criteria. Combinations of controlled terms (MeSH and EMTREE) and keywords were used whenever possible, with "[mh]" representing the $\mathrm{MeSH}$ terms. In addition, other terms not indexed as $\mathrm{MeSH}$ and filters were applied. The key terms used were the following: $((()(()(()(($ "maxillary sinus") OR "schneiderian membrane" [MeSH Terms]) OR "schneiderian membranes" [MeSH Terms]) OR "dental implant" [MeSH Terms]) AND "perfor"”) OR "penetrat") OR "intruding*") OR "sinus perforat" $\mathrm{OR}$ "membrane perforation"”) OR "schneiderian membrane peforation"”). References of full-text-evaluated investigations were also screened. In addition, a manual search in periodontics/ implantology-related journals, including "Clinical Oral Implant Research," "Journal of Dental Research," "Journal of Clinical Periodontology," "Journal of Periodontology," "Clinical Implant Dentistry and Related Research," and "The International Journal of Periodontics \& Restorative Dentistry," from 1980 up to 2018, was also performed to ensure a thorough screening process.

\section{Eligibility criteria}

Articles were included in this systematic review if they met the following inclusion criteria: human prospective or retrospective studies, reporting outcomes of implant placed perforating the sinus floor with implant burs, and without regenerative procedure (lateral sinus lift or transalveolar technique) and graft material. The intrusion into the sinus cavity can occur during drilling or implant placement, with and without punch out Schneiderian membrane. Only studies with at least 6 months of follow-up were included in the qualitative assessment.

The following articles were excluded: case report and case series; animal studies; systematic reviews; in vitro studies; human studies using grafting materials, lateral access sinus lift, and transalveolar technique; and follow-up less than 6 months.

\section{Risk of bias}

Two reviewers (GMR and BE) designed and assessed the proposal for the present project to make sure that the STROBE statement and PRISMA guideline were followed. STROBE stands for an international, collaborative initiative of epidemiologists, methodologists, statisticians, researchers, and journal editors involved in the conduction and dissemination of observational studies,

Table 1 Clinical and radiographic complications reported in the studies

\begin{tabular}{ll}
\hline Clinical complications & Radiographic complications \\
\hline Sinusitis & Thickening of Schneiderian membrane \\
Nasal bleeding, nasal obstruction, nasal secretion & Bone reaction to the implants \\
Deadache and pain or tenderness in the region of the sinus & Sinus pathology \\
\hline
\end{tabular}


Table 2 Characteristics of the included investigations

\begin{tabular}{|c|c|c|c|c|c|c|c|}
\hline Author (year) & Study design & Follow-up (months) & $N$ of patients & $N$ of implants & Smokers & $\begin{array}{l}\text { Length and } \\
\text { diameter }(\mathrm{mm})\end{array}$ & Implant system \\
\hline Shihab 2017 [33] & Retrospective & 60 & 35 & 70 & NA & $5-12 \times 3.0-5.7$ & IDI FMD Nucleoss \\
\hline Ghanem 2014 [32] & Retrospective & 72 & 10 & 10 & NA & NA & NA \\
\hline Nooh 2013 [31] & Prospective & 12 & 56 & 63 & 0 & $\begin{array}{l}4 \times 84.3 \times 105 \times 8 \\
5 \times 10\end{array}$ & Nobel Biocare \\
\hline Kim 2013 [30] & Retrospective & 17.9 & 39 & 87 & NA & $8-9-10-11,5 \times 4-5$ & NA \\
\hline Abi Najm 2013 [29] & Retrospective & 118 & 70 & 83 & 7 & NA & Strauman \\
\hline Tabrizi 2012 [28] & Retrospective & 12 & 13 & 18 & NA & NA & $\begin{array}{l}\text { Astra tech Zimmer } \\
\text { DIO }\end{array}$ \\
\hline Jung 2007 [27] & Retrospective & 10 & 9 & 23 & NA & NA & $\begin{array}{l}\text { Astra tech Osstem } \\
\text { implant }\end{array}$ \\
\hline Branemark 1984 [26] & Retrospective & 120 & 101 & 139 & NA & NA & Branemark system \\
\hline 1-2 phase & Graft material & $\mathrm{CBH}(\mathrm{mm})$ & Penetration (mm) & Evaluation & $\mathrm{ncm}$ & $\begin{array}{l}\text { Membrane } \\
\text { perforation (\%) }\end{array}$ & $\begin{array}{l}\text { Clinic complications } \\
\text { (Pat level) }\end{array}$ \\
\hline 2 & No & $\leq 4$ & $>4$ & rx(opg)-clinic & $>30$ & 100 & 2.1\% epistaxis \\
\hline 2 & No & NA & $\leq 4$ & $\begin{array}{l}\text { rx(opg-MSCT)- } \\
\text { clinic }\end{array}$ & NA & 100 & $0 \%$ \\
\hline 2 & No & $5-8$ & $<4$ & rx(opg)-clinic & $>25$ & 100 & $\begin{array}{l}12.5 \% \text { epistaxis } \\
1.78 \% \text { sinusitis }\end{array}$ \\
\hline 2 & No & $4.2-9.3$ & $1-5$ & rx (opg)-clinic & 25 & 100 & 7.7\% epistaxis \\
\hline 1 & No & $5-8$ & $<4$ & $\begin{array}{l}\text { rx (periapical- } \\
\text { opg)-clinic }\end{array}$ & NA & 100 & $0 \%$ \\
\hline NA & No & NA & $<4$ & $\begin{array}{l}\text { rx (periapical- } \\
\text { CT)-clinic }\end{array}$ & NA & NA & $0 \%$ \\
\hline 2 & No & NA & $>4$ & $\begin{array}{l}r x(C T)- \\
\text { clinic.questionare }\end{array}$ & NA & NA & $0 \%$ \\
\hline 2 & No & NA & NA & rx-clinic & NA & NA & NA \\
\hline Rx complications & Type of prosthesis & $\begin{array}{l}\text { Implant failure } \\
\text { before loading }\end{array}$ & $\begin{array}{l}\text { Implant failure } \\
\text { after loading }\end{array}$ & $\begin{array}{l}\text { Total implant } \\
\text { failure }\end{array}$ & $\begin{array}{l}\text { Survival } \\
\text { rate }(\%)\end{array}$ & Bone loss (mm) & \\
\hline $0 \%$ & NA & 1 & 1 & 2 & $97 \%$ & 0 & \\
\hline $0 \%$ & $49 \mathrm{SC}$ & 0 & 0 & 0 & $100 \%$ & NA & \\
\hline NA & $\begin{array}{l}49 \text { Unilateral SC } 7 \\
\text { Bilateral SC }\end{array}$ & 1 & 0 & 1 & $98 \%$ & NA & \\
\hline NA & $\begin{array}{l}31 \text { SC } 56 \text { splinted } \\
\text { for FA }\end{array}$ & 0 & 0 & 0 & $100 \%$ & +0.05 & \\
\hline $0 \%$ & NA & 0 & 0 & 0 & $100 \%$ & NA & \\
\hline $\begin{array}{l}16 \% \text { (patients) } \\
\text { thickening membrane }\end{array}$ & NA & 0 & 0 & 0 & $100 \%$ & 0 & \\
\hline $\begin{array}{l}60 \% \text { (implants) } \\
\text { thickening membrane }\end{array}$ & NA & 0 & 0 & 0 & $100 \% \%$ & NA & \\
\hline NA & NA & NA & NA & $30 \%$ & $70 \%$ & NA & \\
\hline
\end{tabular}

CHB crestal bone height, $m m$ millimeters, SC single crown, FA full arch restoration, NA not available, $r x$ radiography, opg orthopantomography, CT computerized tomography, MSCT multi-slice computerized tomography

and consists of a 22-item checklist to be fulfilled in a systematic review.

\section{Qualitative assessment}

The quality of the selected randomized controlled trials (RCTs) was established from the randomized clinical trial checklist of the Cochrane Center and CONSORT (Consolidated Standards of Reporting Trials) statement, which provided guidelines for the following parameters: (1) sequence generation, (2) allocation concealment method, (3) masking of the examiner, (4) address of incomplete outcome data, and (5) free of selective outcome reporting. The Newcastle-Ottawa scale (NOS) was used to assess the risk of bias of non-randomized studies. This was performed by two investigators (GMR and BE). Cohen's kappa coefficient was used to assess inter-rater agreement.

\section{Statistical analysis}

The R 3.0.2 software package was used to perform the meta-analysis. The primary variable was implant survival rate. The secondary variable was the relationship between the degree of penetration and clinical and radiological 
complication. The analysis was performed using the methodology described below. The pooled weighted mean (WM) and the 95\% confidence interval (CI) of each variable were estimated using a computer program (Comprehensive Meta-analysis version 2, Biostat). Random effects meta-analyses of the selected studies were applied to account for potential bias arising from methodology.

\section{Study of heterogeneity}

Heterogeneity was assessed based on calculation of the $I^{2}$ statistic (percentage variability of estimated effect that can be attributed to the heterogeneity of the effects) and the null statistic test. Galbraith graphs displayed the degree of heterogeneity. In studies where great heterogeneity was detected, a sensitivity analysis was performed to determine its source. Funnel plots and the Egger test were used to assess risk of bias of the accepted statistical significance level of $5 \%(p=0.05)$.

\section{Results}

\section{Study screening}

An initial screening yielded a total of 3551 publications of which 26 potentially relevant articles were selected after an evaluation of their titles and abstracts. Full text of these articles was obtained and evaluated thoroughly. Of these, eight articles [26-33] (Table 2) fulfilled the inclusion criteria and subsequently were included in the qualitative analysis (Fig. 2). Reasons for exclusion are displayed in supplementary (Table 3).

The NOS was used to appraise the quality of included studies for a proper understanding of nonrandomized studies. Because no nonrandomized controlled trials were found in the screening process, the 17 included studies were analyzed with NOS. The level of agreement between the reviewers regarding study inclusion calculated using Cohen kappa statistic interagreement rate of 0.8 was reached. A mean NOS score of $5.1 \pm 1.4$ was obtained after discussing the disagreements between the examinees (GMR and BE) and third consultant (FL-A).

\section{Implant survival}

Eight studies [26-31, 33] (Table 2) provide information on the survival rate, which consisted of a global sample of 493 implants, of which a subtotal of 340 reported the degree of penetration (Fig. 3), with a mean follow-up of 52.7 months. The implant survival between the different

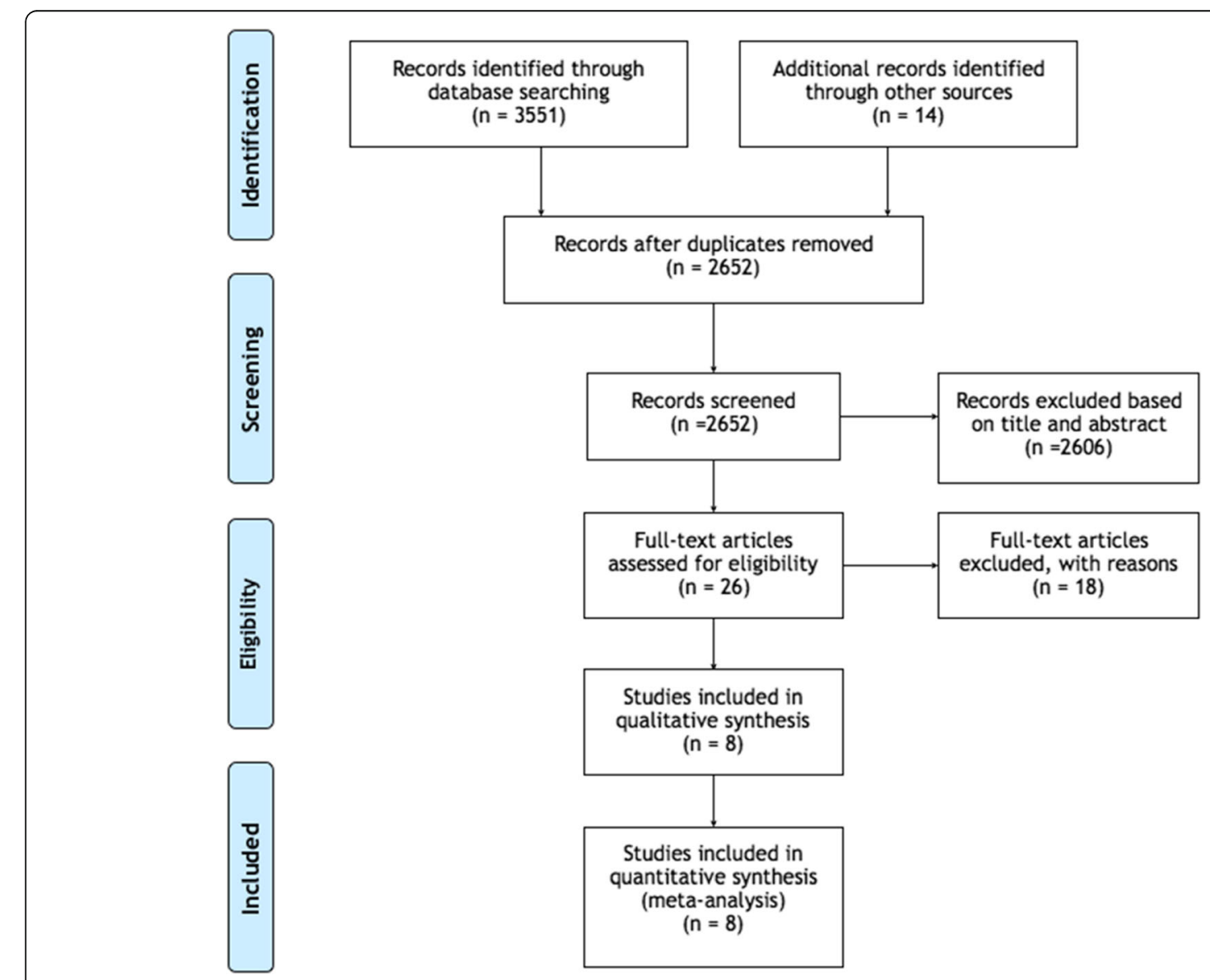

Fig. 2 PRISMA flowchart of the screening process 
Table 3 Articles excluded and reasons for exclusion

\begin{tabular}{ll}
\hline Reason for exclusion & Investigations \\
\hline Study design (case series or case report) & Kim et al. (2017), Hatano et al. (2007) \\
$\begin{array}{ll}\text { Different grafting technique (lateral sinus lift or } \\
\text { transalveolar technique) }\end{array}$ & $\begin{array}{l}\text { Jensen et al. (1994), Winter et al. (2002), Toffler et al. (2004), Chappuis et al. (2009), Soltan et al. } \\
\text { (2011), Xiao et al. (2011), Cricchio et al. (2011), Scala et al. (2012), Bruschi et al. (2013), } \\
\text { Kadkhodazadeh et al. (2013), Pjetursson et al. (2014), Monje et al. (2016), Falah et al. (2016), Markovic } \\
\text { et al. (2017) }\end{array}$ \\
\hline Type of implant (Zygoma implant) & Pjetursson et al. (2004) \\
\hline
\end{tabular}

authors range from 70 to $100 \%$, being the weighted mean survival rate 95.6\% with an IC 95\% [88.4100] (Fig. 4a). A re-estimation is proposed excluding Brånemark et al. [26] from the meta-analysis, due to the year of publication which is before 2000, implant surface, and the surgical technique that can lead to these low survival rates of $70 \%$. The seven articles [27-33] of the last 10 years remain in the calculations, being the weighted survival rate of $99.3 \%$ with an IC 95\% [98.4100]. With regard to the influence of the penetration level, it was categorized into two levels with a cutoff point of $4 \mathrm{~mm}$ (Fig. 4b). It was analyzed if there were any differences in survival according to this aspect. For this, six studies contribute with 267 implants [27-33]. The estimated survival rates were $99.5 \%$ CI [98.2100] in implant penetrating $\leq 4 \mathrm{~mm}$ and $98.5 \% \mathrm{CI}$ [96.6100] in implant penetrating $>4 \mathrm{~mm}$ (Fig. 3). There were no statistical significant differences in survival according to the degree of penetration ( $p=0.403)$ (Fig. $4 \mathrm{~b})$.

\section{Analysis of clinical complications}

Seven studies [27-33] provide information on clinical complications with a global sample of 232 patients. Clinical complications among the different authors range from 0 to $14.3 \%$, being the weighted mean complication rate 3.4\% with an IC 95\% [0 7.5] (Fig. 4c) Clinical complications analyzed in the studies were sinusitis, nasal bleeding, nasal obstruction, nasal secretion, mucopurulent drainage, headache and pain or tenderness in the region of the sinus, facial pain-pressure-fullness, and decreased sense of smell. The most common clinical complication was epistaxis, reported in three studies [30, 31,33 ], followed by sinusitis, reported in only one study [31]. Other complications did not appear. With regard to the influence of penetration level, 193 patients can be included in the analysis. The estimated complication rate was $3.54 \%$ CI [0 9.62] in implant penetrating $\leq 4 \mathrm{~mm}$ and $1.05 \%$ IC [0 9.63] in implant penetrating $>4 \mathrm{~mm}$. The differences were not statistically significant in the rate of clinical complications according to the degree of penetration $(p=0.642)$.

\section{Analysis of radiographic complications}

Five studies [27-29, 32, 33] provide information on the radiographic complication rate with a global sample of 137 patients. Complications between the different authors range from 0 to $60 \%$, being the weighted complication rate $14.8 \%$ with an IC 95\% [0 37.1] (Fig. 4d). Radiographic complications analyzed in the articles were thickening of the Schneiderian membrane, bone reaction to the implant, and any sinus pathology. The most common radiographic complication was thickening of the Shneiderian membrane, reported in two studies $[27,28]$ in $16 \%$ of patients in Tabrizi et al. [28] study and $60 \%$ of the implants in Jung et al. [27] study. Other complications did not appear.

With regard to the influence of the penetration level, the estimated complication rates are 5.29\% CI [0 33.8] in implant penetrating $\leq 4 \mathrm{~mm}$ and $29.3 \% \mathrm{CI}[064.6]$ in implant penetrating $>4 \mathrm{~mm}$. There were no statistical significant differences in the radiographic complication rate according to the degree of penetration $(p=0.301)$.
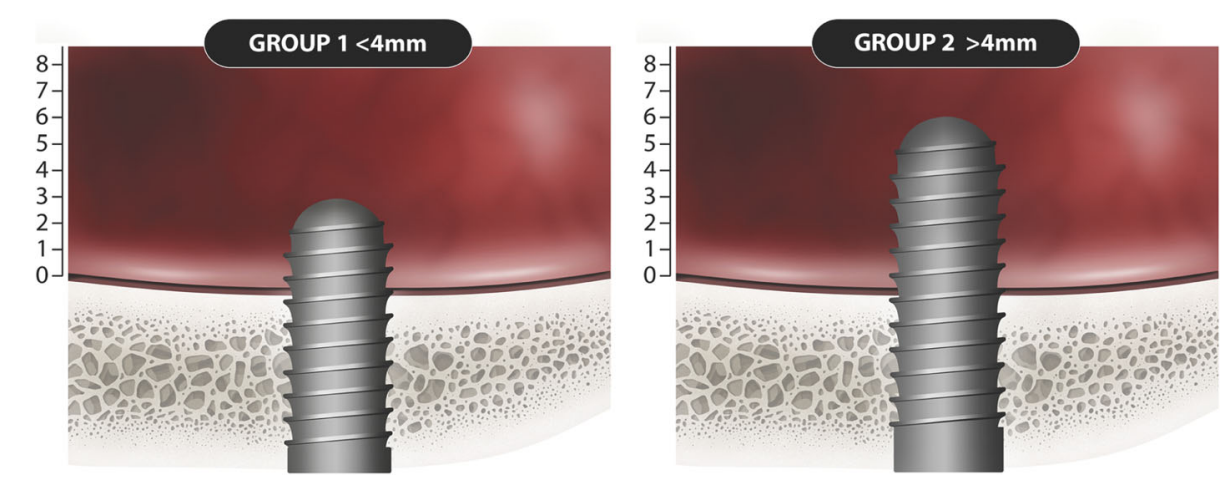

Fig. 3 Graphic representation of group $1 \leq 4 \mathrm{~mm}$ penetration and group $2>4 \mathrm{~mm}$ penetrations 
A

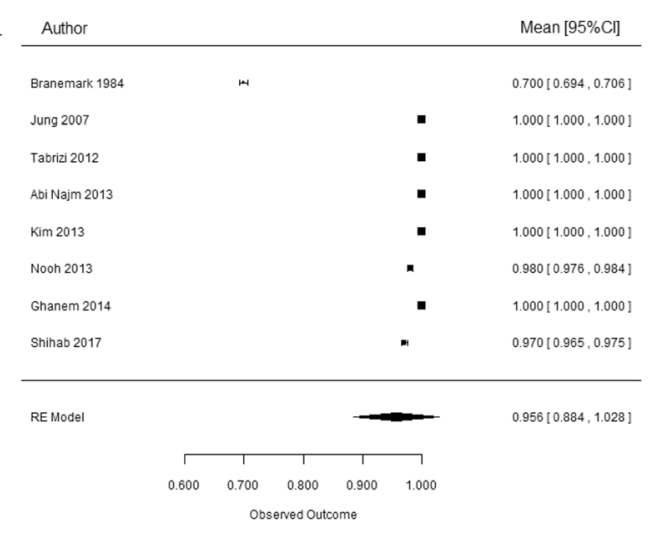

B

Author

Mean $[95 \% \mathrm{Cl}]$

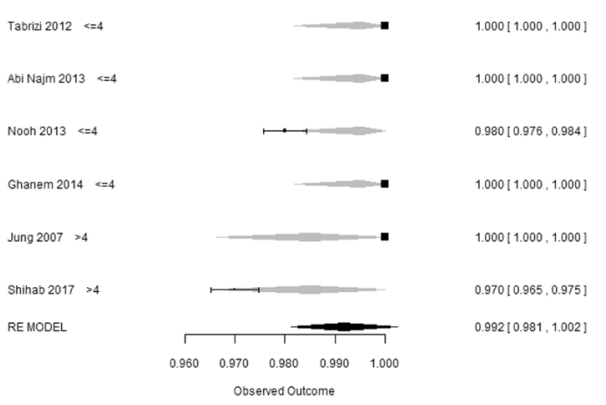

C

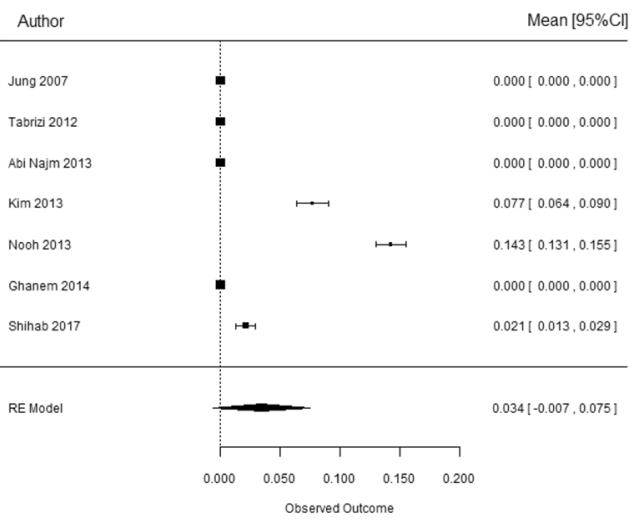

$\mathrm{D}$

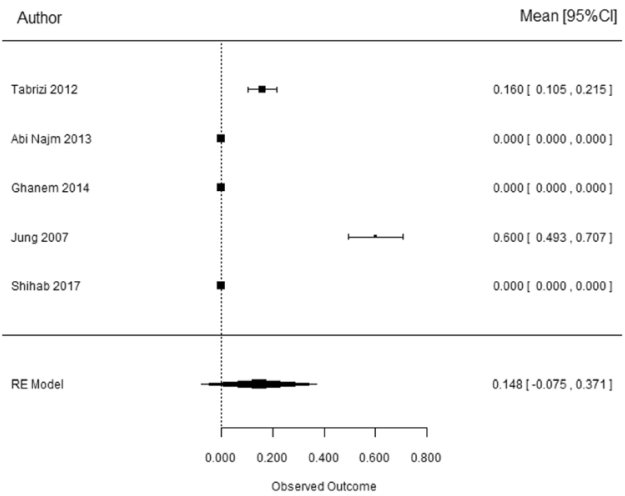

Fig. 4 Statistical analysis for different variables. a Weighted mean survival rate. $\mathbf{b}$ Implant survival rate according to degree of penetration. c Analysis of clinical complications. d Analysis of radiographic complications

\section{Discussion}

Pneumatization of the maxillary sinus and resorption of the residual alveolar ridge following tooth extraction can compromise the dental implant placement. Similarly, extension of the dental implants inside the maxillary sinus cavity is not rare. Some studies have observed some differences in relation to the depth of the implant extension inside the sinus cavity. When the implants penetrate inside of the sinus cavity less than $2 \mathrm{~mm}$, spontaneous covering of the implants with the sinus mucosa seems to occur [34, 35]. Also, new bone formation above dental implants has been described, especially if the implants exposed to the maxillary sinus do not tear the Schnederian membrane [34-38]. Nevertheless, when the implant extension inside the maxillary sinus is greater (more than $2 \mathrm{~mm}$ ), the maxillary membrane do not repair spontaneously and debris accumulate on the exposed surfaces of the implants that were not covered by bone inside the antral cavity [34], which could lead to sinusitis. However, the long-term consequences of debris accumulation over the implants extended inside the maxillary sinus and perforating the Schneiderian membrane were not systematically evaluated before.

In relation to the long-term consequence of these different levels of implant protrusion, it was observed in this review that there were no statistically significant differences in implant survival, between implant penetrating $\leq 4 \mathrm{~mm}$ or $>4 \mathrm{~mm}$, with a survival rate of $99.5 \%$ and $98.5 \%$ respectively.

Survival rate of the present review is in accordance with survival rates reported in a systematic review by Corbella et al. [39] in which the analyzed survival rates of different techniques for the treatment of atrophic posterior maxilla were as follows: short implants showed a survival rate from 86.5 to $98.2 \%$, osteotome technique showed a survival rate from 95.4 to $100 \%$, and sinuses augmentation through lateral technique showed an implant survival rate from 75.57 to $100 \%$.

The secondary outcome of this review was the analysis of the clinical and radiological complications related to the penetration of implants in the maxillary sinus. Clinical complication among the different authors ranges from 0 to $14.3 \%$, with a weighted mean complication rate of $3.4 \%$, without finding statistical difference according to the level of implant penetration. The most common clinical complication was epistaxis, which can be considered a minor complication and that did not lead to major complications. Radiographic complication has also been shown low, weighted complication rate of 
$14.8 \%$, without finding statistical difference according to the level of implant penetration. The most common complication was thickening of sinus membrane without having relevance at the clinical level. This is in concordance with the mongrel-dog study of Jung et al. [35], who observed after 6 months follow-up that the mucosa in the maxillary sinus cavity showed no inflammatory signs when dental implants perforating inside the maxillary sinus, suggesting that the extending implants do not make the maxillary sinus vulnerable to complications and do not cause any effect to the sinus physiology and resulting with no local or systemic pathology at all.

Consequently, it seems that maxillary sinus changes in relation to protruded implants inside the sinus cavity and does not statically affect to implant survival rate neither to clinical nor radiographic complications.

Several limitations could be described for the present review. Firstly, there is a lack of a control group in the included studies, to compare outcomes and complications, with implant placed in native bone, or with regenerative techniques. Second limitation was related to the types of included studies being seven retrospectives [26-33] and one prospective study [31]. Third, the lack of a reliable method to evaluate the millimeters of implants intruded inside the maxillary sinus and to assess sinus membrane perforation or not. Fourth, the analysis of the radiographic complications has been analyzed only in three studies with computerized tomography and in two studies by orthopantomographies and periapical radiographs, taking into account the difficulties of analyzing radiological complications in periapicals and orthopantomographies.

Future research should focus on performing randomized studies comparing implant intrusion in the maxillary sinus versus regenerative techniques, focusing on the rate of complications and patient outcomes. Further, it would be interesting to study the possibility of placing short implants and thus avoid access to the maxillary sinus.

\section{Conclusions}

The current review showed that the exposure of dental implants in the sinus cavity without the augmentation procedure or graft materials shows a high survival rate of $95.6 \%$, without statistically significant differences according to the level of penetration (lower or higher to $4 \mathrm{~mm}$ ). Changes in maxillary sinuses in relation to protruding implants within the sinus cavity do not statically affect clinical or radiographic complications of $3.4 \%$ and $14.8 \%$ respectively. Although caution is necessary, it is not advised to carry out this technique intentionally, since the supporting literature is based only on retrospective studies. Further research is needed, with prospective and randomized studies that directly compare different techniques in equal local and systemic conditions to explore the complications and outcomes of the patient center.

\section{Acknowledgements}

The authors want to thank Mr Juan Luis Gómez Martínez for the support in the statistical analysis.

\section{Funding}

Not applicable

Availability of data and materials

Not applicable

\section{Disclosure}

The authors do not have any financial interests, either directly or indirectly, in the products or information listed in the paper.

\section{Authors' contributions}

GMR, BE and FSLA formed an active part of the systematic review. FHA participated actively in the revision and correction of the article along with JGA and HLW. All colleagues mentioned took part in the development of this article. All authors read and approved the final manuscript.

\section{Ethics approval and consent to participate}

Not applicable

\section{Consent for publication}

Not applicable

\section{Competing interests}

Gian Maria Ragucci, Basel Elnayef, Fernando Suárez López del Amo, Hom-Lay Wang, Federico Hernández-Alfaro, and Jordi Gargallo-Albiol declare that they have no competing interests.

\section{Publisher's Note}

Springer Nature remains neutral with regard to jurisdictional claims in published maps and institutional affiliations.

\section{Author details}

${ }^{1}$ Department of Oral and Maxillofacial Surgery, International University of Catalonia, C/Josep Trueta Sn, Sant Cugat del Vallés, C.P 08195 Barcelona, Spain. ${ }^{2}$ Department of Periodontics, University of Oklahoma Health Sciences Center - College of Dentistry, Oklahoma City, OK, USA. ${ }^{3}$ Department of Periodontics and Oral Medicine, University of Michigan School of Dentistry, Ann Arbor, MI, USA.

Received: 9 October 2018 Accepted: 6 January 2019

Published online: 05 February 2019

\section{References}

1. Roccuzzo M, Bonino L, Dalmasso P, Aglietta M. Long-term results of a three arms prospective cohort study on implants in periodontally compromised patients: 10-year data around sandblasted and acid-etched (SLA) surface. Clin Oral Implants Res. 2014;25(10):1105-12.

2. Esposito M, Grusovin MG, Rees J, Karasoulos D, Felice P, Alissa R, Worthington $\mathrm{H}$, Coulthard P. Effectiveness of sinus lift procedures for dental implant rehabilitation: a Cochrane systematic review. Eur J Oral Implantol. 2010;3(1):7-26.

3. Felice P, Soardi E, Pellegrino G, Pistilli R, Marchetti C, Gessaroli M, Esposito M. Treatment of the atrophic edentulous maxilla: short implants versus bone augmentation for placing longer implants: five-month post-loading results of a pilot randomised controlled trial. Eur J Oral Implantol. 2011;4(3): 191-202.

4. Esposito M, Cannizzaro G, Soardi E, Pistilli R, Piattelli M, Corvino V, Felice P. Posterior atrophic jaws rehabilitated with prostheses supported by $6 \mathrm{~mm}$ long, 4 mm-wide implants or by longer implants in augmented bone. Preliminary results from a pilot randomised controlled trial. Eur J Oral Implantol. 2012:5(1):19-33.

5. Felice P, Pistilli R, Piattelli M, Soardi E, Corvino V, Esposito M. Posterior atrophic jaws rehabilitated with prostheses supported by $5 \times 5 \mathrm{~mm}$ implants with a novel nanostructured calcium-incorporated titanium surface or by longer implants in augmented bone. Preliminary results from a randomised controlled trial. Eur J Oral Implantol. 2012;5(4):149-61. 
6. Felice P, Pistilli R, Barausse C, Bruno V, Trullenque-Eriksson A, Esposito M. Short implants as an alternative to crestal sinus lift: a 1-year multicentre randomised controlled trial. Eur J Oral Implantol. 2015;8(4):375-84.

7. Sorní M, Guarinos J, Peñarrocha M. Implants in anatomical buttresses of the upper jaw. Med Oral Patol Oral Cir Bucal. 2005;10(2):163-8.

8. Chrcanovic BR, Albrektsson T, Wennerberg A. Survival and complications of zygomatic implants: an updated systematic review. J Oral Maxillofac Surg. 2016 Oct;74(10):1949-64.

9. Tuminelli FJ, Walter LR, Neugarten J, Bedrossian E. Immediate loading of zygomatic implants: a systematic review of implant survival, prosthesis survival and potential complications. Eur J Oral Implantol. 2017;10(1):79-87.

10. Curi MM, Cardoso CL, de Ribeiro C. Retrospective study of pterygoid implants in the atrophic posterior maxilla: implant and prosthesis survival rates up to 3 years. Int J Oral Maxillofac Implants. 2015;30(2):378-83.

11. Boyne PJ, James RA. Grafting of the maxillary sinus floor with autogenous marrow and bone. J Oral Surg. 1980;38(8):613-6.

12. Tatum H.Jr. Maxillary and sinus implant reconstructions. Dent Clin N Am 1986;30(2):207-229.

13. Summers RB. A new concept in maxillary implant surgery: the osteotome technique. Compendium. 1994;15(2):154-6.

14. Wallace SS, Froum SJ. Effect of maxillary sinus augmentation on the survival of endosseous dental implants. A systematic review. Ann Periodontol. 2003 Dec;8(1):328-43.

15. Del Fabbro M, Rosano G, Taschieri S. Implant survival rates after maxillary sinus augmentation. Eur J Oral Sci. 2008 Dec;116(6):497-506.

16. McGowan DA, Baxter PW, James J. The maxillary sinus and its dental implications. Oxford: Wright, Butter- worth-Heinemann Ltd; 1993. p. 1-25.

17. Chanavaz M. Sinus graft procedures and implant dentistry: a review of 21 years of surgical experience (1979-2000). Implant Dent. 2000;9(3):197-206.

18. Hernandez-Alfaro F, Torradeflot MM, Marti C. Prevalence and management of Schneiderian membrane perforations during sinus-lift procedures. Clin Oral Implants Res. 2008 Jan;19(1):91-8.

19. Stacchi C, Andolsek F, Berton F, Perinetti G, Navarra CO, Di Lenarda R. Intraoperative complications during sinus floor elevation with lateral approach: a systematic review. Int J Oral Maxillofac Implants. 2017;32(3):10718.

20. Froum SJ, Khouly I, Favero G, Cho SC. Effect of maxillary sinus membrane perforation on vital bone formation and implant survival: a retrospective study. J Periodontol. 2013 Aug;84(8):1094-9.

21. de Almeida Ferreira $C E$, Martinelli $C B$, Novaes $A B$, Jr Pignaton TB, Guignone CC, Goncalves de Almeida AL, et al. Effect of maxillary sinus membrane perforation on implant survival rate: a retrospective study. Int J Oral Maxillofac Implants. 2017;32(2):401-7.

22. Karabuda C, Arisan V, Ozyuvaci H. Effects of sinus membrane perforations on the success of dental implants placed in the augmented sinus. J Periodontol. 2006 Dec;77(12):1991-7.

23. Ardekian L, Oved-Peleg E, Mactei EE, Peled M. The clinical significance of sinus membrane perforation during augmentation of the maxillary sinus. $J$ Oral Maxillofac Surg. 2006 Feb;64(2):277-82

24. Anavi Y, Allon DM, Avishai G, Calderon S. Complications of maxillary sinus augmentations in a selective series of patients. Oral Surg Oral Med Oral Patho Oral RadiolEndod. 2008;106(1):34-8.

25. Van den Bergh JP, Ten Bruggenkate CM, Disch FJ, Tuinzing DB. Anatomica aspects of sinus floor elevations. Clin Oral Implants Res. 2000;11(3):256-65.

26. Branemark PI, Adell R, Albrektsson T, Lekholm U, Lindstrom J, Rockler B. An experimental and clinical study of osseointegrated implants penetrating the nasal cavity and maxillary sinus. J Oral Maxillofac Surg. 1984 Aug;42(8):497-505.

27. Jung $\mathrm{JH}$, Choi BH, Jeong SM, Li J, Lee $\mathrm{SH}$, Lee $\mathrm{HJ}$. A retrospective study of the effects on sinus complications of exposing dental implants to the maxillary sinus cavity. Oral Surg Oral Med Oral Pathol Oral Radiol Endod. 2007 May;103(5):623-35.

28. Tabrizi R, Amid R, Ozkan TB, Khorshidi HDDS, Langner NJ. Effects of exposing dental implant to the maxillary sinus cavity. J Craniofac Surg. 2012 23:767-9.

29. Abi Najm S, Malis D, El Hage M, Rahban S, Carrel JP, Bernard JP. Potential adverse events of endosseous dental implants penetrating the maxillary sinus: long-term clinical evaluation. Laryngoscope. 2013;123(12):2958-61.

30. Kim HY, Yang JY, Chung BY, Kim JC, Yeo IS. Peri-implant bone length changes and survival rates of implants penetrating the sinus membrane at the posterior maxilla in patients with limited vertical bone height. J Periodontal Implant Sci. 2013;43:58-63.
31. Nooh N. Effect of Schneiderian membrane perforation on posterior maxillary implant survival. Journal of International Oral Health. 2013;5(3):28-34.

32. Ghnaem A, Gad HM. The influence of exposing dental implants to the maxillary sinus cavity on sinus complications and implant survival rate: 6 years prospective follow-up. Egypt Dent J. 2014;60(3):2-9.

33. Shihab Ol. Intentional penetration of dental implants into the maxillary sinus: a retrospective study. Zanco J Med Sci. 2017;21(1):1536-9.

34. Schwarz L, Schiebel V, Hof M, Ulm C, Watzek G, Pommer B. Risk factors of membrane perforation and postoperative complications in sinus floor elevation surgery: review of 407 augmentation procedures. J Oral Maxillofac Surg. 2015;73:1275-82

35. Jung JA, Choi BH, Zhu SJ, Lee SH, Huh JY, You TM, Lee HJ, Li J. The effects of exposing dental implants to the maxillary sinus cavity on sinus complications. Oral Surg Oral Med Oral Pathol Oral Radiol Endod. 2006;102:602-5.

36. Thor A, Sennerby L, Hirsch JM. Bone formation at the maxillary sinus floor following simultaneous elevation of the mucosal lining and implant installation without graft material: an evaluation of 20 patients treated with 44 Astra tech implants. J Oral Maxillofac Surg. 2007;65:64-72.

37. Lundgren S, Andersson S, Gualini F, Sennerby L. Bone reformation with sinus membrane elevation: a new surgical technique for maxillary sinus floor augmentation. Clin Implant Dent Relat Res. 2004;6:165-73.

38. Petruson B. Sinuscopy in patients with titanium implants in the nose and sinuses. Scandinavian J Plastic Recons Surg Hand Surg. 2004;38:86-93.

39. Corbella S, Taschieri S, Del Fabbro M. Long-term outcomes for the treatment of atrophic posterior maxilla: a systematic review of literature. Clin Implant Dent Relat Res. 2015 Feb;17(1):120-32.

\section{Submit your manuscript to a SpringerOpen ${ }^{\circ}$ journal and benefit from:}

- Convenient online submission

- Rigorous peer review

- Open access: articles freely available online

High visibility within the field

- Retaining the copyright to your article

Submit your next manuscript at $>$ springeropen.com 